\title{
¿Feminismos "amefricanos”?: Trayectorias políticas e intelectuales de Lélia Gonzalez y Alicia Camacho durante la década de 1980
}

"AMEFRICAN" FEMINISMS?: INTELLECTUAL TRAJECTORIES OF LÉLiA Gonzalez de Almeida and Alicia Camacho during the ig8os

\author{
Lorena Ardito \\ Universidad de Chile \\ lorena.ardito@gmail.com
}

RESUMEN: El artículo analiza las trayectorias de dos autoras "amefricanas": Lélia Gonzalez de Almeida (Belo Horizonte, 1935 - Río de Janeiro, 1994) y Alicia Camacho Garcés (Buenaventura, 1940 - Buenaventura, 2017), en la década en que tanto la militancia como la producción textual de ambas es más prolífera. Se recurre a la noción de lugar de enunciación (o da fala) para analizar el contexto de sus obras y un corpus característico de algunas de las principales temáticas y giros políticos, intelectuales e identitarios que las autoras experimentan en el periodo. A través de una mirada en contrapunto, se busca enfatizar la singularidad de sus planteamientos, reconociendo su originalidad y potencia tanto dentro como fuera de los feminismos negros, interseccionales, de(s)coloniales y antirracistas contemporáneos.

Con ello, se pretende aportar a la comprensión de la enorme diversidad que conforman los pensamientos críticos desarrollados por mujeres racializadas en Nuestra América. 
Palabras clave: Lélia Gonzalez, Alicia Camacho, lugar de enunciación, movimiento negro, pensamientos racializados.

Aвsтract: The article analyzes the political and intellectual trajectories of two "Amefricans" authors: Lélia Gonzalez de Almeida (Belo Horizonte, 1935 - Río de Janeiro, 1994) and Alicia Camacho Garcés (Buenaventura, 1940 - Buenaventura, 2017), in the decade that their political militancy and textual production is most prolific. The notion of place of enunciation (or da fala) is used to analyze their works' context and a characteristic corpus of some main politic, intellectual and identity turnarounds experienced by the authors during the decade. Using a contrapuntual approach, the article attempts to emphasize the singularity of their approaches, recognizing their originality and power both within and outside the contemporary black, intersectional, decolonial and anti-racist feminisms.

The discussion intends to contribute into the understanding of the enormous diversity that forms critical thoughts developed by racialized women in Nuestra America.

Keywords: Lélia Gonzalez, Alicia Camacho, place of enunciation, black movement, racialized thoughts.

\section{Tensionando el punto de Partida}

¿Descubrimiento de qué? Ay de América Latina... Alicia Camacho, 1992.

Durante las décadas de 1950, 1960 y 1970 del siglo pasado, el movimiento negro estadounidense -en sus versiones religiosas, seculares, cívicas, radicales, académicas y populares ${ }^{1}$ - se transformó en uno de

1 Pensando en expresiones disímiles (incluso a veces contrapuestas) que emergen en la búsqueda de la liberación del "sujeto histórico negro", como la Nación del Islam, la Teología de la Liberación Negra, el Movimiento por los Derechos Políticos y Civiles, y el Black Power (que incluye al Partido Pantera Negra y la Liga de Obreros Negros Revolucionarios, entre otros). Pero también al surgimiento de los black studies, el hip hop y el feminismo negro (que reivindica la especificidad e imbricación de las opresiones y horizontes de liberación de "la sujeta histórica negra”). 
los referentes más relevantes en las luchas por la descolonización y liberación nacional que entonces se desenvolvieron tanto en América como en el propio continente africano (Lao-Montes 218). No obstante, parece menos frecuente atribuir dicha relevancia política, intelectual, cultural e incluso económica, a las luchas y pensamientos que han desarrollado las y los descendientes de africanos en Nuestra América, como la llamó José Martí. La resonancia de estas luchas trasciende desde la Revolución Haitiana a las guerras de independencia; del panafricanismo a las luchas de liberación africanas y afroestadounidenses; del movimiento de la negritud a las reivindicaciones del Orgullo Negro/ Afro (Black is Beautiful / Beleza negra); o desde los marxismos negros a las luchas anticapitalistas y anticoloniales, por mencionar algunas de sus expresiones más relevantes y originales (Lao-Montes 217). Me refiero a ese complejo y extendido proceso de silenciamiento que el historiador afrocolombiano Santiago Arboleda ha definido en torno a la idea de "clandestinización pública", la cual se expresa de formas heterogéneas y sistemáticas, operando "fundamentalmente en cuatro órdenes o focos epistemológicos: 1) el escamoteo; 2) la tribalización; 3) la trivialización y 4) la invisibilización" (6). Esta clandestinización también tiene lugar en los feminismos negros y antirracistas, como ha investigado la politóloga y activista afromexicana Gabriela González Ortuño, quien ha seguido la pista del pensamiento feminista y panafricanista en autoras jamaiquinas del primer tercio del siglo XX -Una Marson y Amy Jacques-Garvey-, radicadas en Nueva York en los albores del Black Feminism y el Black Power, cuyos escritos y planteamientos influyeron en dichos movimientos. Como concluye González, "los intercambios entre el mar Caribe y el país del norte eran más fluidos de lo que parecen” (247).

Desde las periodizaciones y tematizaciones feministas "por oleadas", constatamos cómo esta tensión dual entre visibilidad y ocultamiento se expresa permanentemente. Lo vemos en la "invisibilización" de los feminismos sindicalistas (socialistas y anarquistas) frente a los movimientos sufragistas; en la "trivialización" de las disidencias sexo-genéricas, frente a la universalización de la categoría teórico-política "mujer" (Espinosa-Miñoso 9); en la "tribalización" de los feminismos negros, de color, antirracistas, chicanos, musulmanes, tercermundistas o de frontera, subsumidos por la emergencia desterritorializada de feminismos interseccionales, poscoloniales o de(s)coloniales (Abdala); o en el escamoteo hacia las mujeres y disidencias negras por parte de sus 
compañeros, acusadas de "dividir la lucha antirracista", como también desde sus pares feministas, por "atomizar el movimiento entre 'negras' y 'no negras'” (Curiel, La Red 9).

Clase, sexo/género, raza y militancia se configuran así como escenarios complejos y desiguales, en los que se moviliza una diversidad de etiquetas identitarias para disputar la tensión permanente entre diversas posiciones de inclusión y exclusión. Sin embargo, y paradójicamente, si bien estas etiquetas permiten destacar trayectorias de lucha y pensamiento clandestinizadas, operan al mismo tiempo como un pesado mecanismo de invisibilización. Un lente engañoso que, en vez de favorecer la compresión de singularidades, homogeneiza una enorme diversidad de expresiones políticas, intelectuales y culturales. Es lo que sucede con los feminismos negros caribeños y latinoamericanos pensados como mera extensión del black feminism estadounidense (González Ortuño 240-241); es decir, desconociendo sus complejidades y aportes peculiares. Pero también con los pensamientos críticos desarrollados por mujeres racializadas fuera de la órbita feminista en tanto horizonte epistémico y político, como advierte la antropóloga y activista maya kaqchikel Aura Cumes, en sus reflexiones en torno a la "segregación comprensiva" ("Mujeres" 4-6), como advierte en el siguiente fragmento de entrevista ("Un patriarcado"):

Cuando las mujeres indígenas nos nombramos feministas casi que se piensa que porque somos feministas es que hemos creado consciencia de lucha $[\ldots]$ y eso no es así, yo no me quiero subordinar en ningún momento bajo la epistemología feminista como única forma de existencia $(\mathrm{s} / \mathrm{i})$.

Es desde esta perspectiva que el presente artículo se propone analizar algunas especificidades de las trayectorias en contrapunto de Lélia Gonzalez de Almeida y Alicia Camacho Garcés durante la década de 1980. Estas dos intelectuales y activistas amefricanas ponen en tensión el punto de partida feminista o antipatriarcal como eje de lectura único o suficiente, aun cuando su práctica y pensamiento, especialmente en el caso de Lélia, son indudables expresiones de lo que podríamos denominar "feminismos amefricanos".

Hablamos de autoras cuyas trayectorias son irreductibles "en la popular frase de la triple opresión" (Cumes, "Mujeres" 6), pues también nos remiten a las tensiones internas en las condiciones de clase, sexo/género y 
colonialidad/racialización, desbordando la óptica teórico-política de los feminismos interseccionales y de(s)coloniales, por la potencia, complejidad y multidimensionalidad de sus obras y experiencias. Un análisis que, utilizando la noción de lugar de enunciación como ruta de acceso, se concentra justamente en el periodo en que tanto la militancia como la producción textual de ambas es más lúcida, prolífica y congregante: la década de instalación del neoliberalismo y sus peculiares formas de despojo y violencia contemporáneas.

\section{Pensamientos RACializados y LUGAR DE ENUNCIACIÓN}

El riesgo que asumimos aqui es el del acto de hablar con todas las implicaciones. Exactamente porque hemos sido hablados e infantilizados...

Lélia Gonzalez, 1984.

Comprendo la "raza" como un constructo ideológico y cambiante que en el periodo tardo-medieval cristalizó en torno a las ideas de pureza de sangre y linaje, y que durante la consolidación del régimen esclavista (aunque más decididamente con la emergencia del racismo científico) comenzó a operar como un eficiente dispositivo de jerarquización y moralización de la diversidad humana (Wade 39-40), caricaturizando rasgos fenotípicos específicos como ejes de clasificación y demarcación sobre los cuerpos (Ortiz 23-25). Ello, en un contexto de expansión del colonialismo y desarrollo del capitalismo que ha implicado la naturalización de la jerarquización humana y, en consecuencia, la conveniente y eficaz generación de un dispositivo de dominación social que, aun cuando se actualice, permanece anclado a un patrón colonial y global de configuración y ejercicio de poder, como ha indagado el sociólogo peruano Aníbal Quijano.

Paradójicamente, la idea de raza nos remite a una identidad fija que oculta el carácter procesual y por tanto dinámico de su propia construcción. Advirtiendo aquello, en las últimas décadas ha venido cobrando fuerza la noción de "racialización" como una práctica cotidiana al tiempo que un proceso histórico de producción e inscripción corporal y subjetiva de marcas o estigmas sociales. Estas derivan tanto de la experiencia de la colonialidad como del proceso monolítico de conformación de identidades nacionales, "en que determinados rasgos corporalizados son considerados 
jerárquicamente inferiores frente al 'nosotros', justificando distintas formas de violencia, desprecio, intolerancia, explotación y humillación” (Tijoux y Palominos 250). Un proceso que opera exacerbando y particularizando la diferencia del "otro" racializado, pero también universalizando la especificidad que es privilegiada por este sistema permanente de clasificación.

Es lo que observa el psiquiatra, intelectual y revolucionario martiniqueño Frantz Fanon en Piel negra, máscaras blancas, cuando critica el existencialismo humanista de Jean-Paul Sartre frente a la barbarie nazi desde su condición de "negro antillano", una condición semántica previa a la marca corporal colonial vivida, reconociendo que "no soy yo quien crea un sentido para mí, sino que el sentido estaba ahí, preexistente, esperándome" (127). Fanon apunta al problema de la producción colonizada de subjetividades, proponiéndose "liberar al hombre de color de sí mismo" (42), pues el racismo introyectado lo lleva a desarraigarse de su propia historia, querer ser el "otro blanco", ocupar su lugar, suplantarlo. Un llamado a impugnar, resignificar y disputar las mismas identidades y subjetividades racializadas desde horizontes de pensamiento y acción descolonizadores.

Los pensamientos racializados pueden ser comprendidos, entonces, como aquellas producciones discursivas que evidencian las marcas de su racialización, ya sea por procesos de clandestinización o señalamiento externos, o bien por su propia adscripción -temporal o permanente- a identidades racializadas como lugar de enunciación, crítica y deconstrucción. Una idea que nos remite a aquello que desde Gayatri Spivak se conoce como "esencialismos estratégicos", aunque sin la carga esencializante y fija que tensiona y limita el carácter emancipatorio de su propuesta.

Hablamos más bien de una larga reivindicación de pensamientos críticos autoenunciados como "propios" en la región, rastreables en las nociones de "epistemes alternativas" (Rivera Cusicanqui, Sociología 17)

2 Concepto recuperado por autores como el antropólogo colombiano Eduardo Restrepo, quien tensiona las críticas académicas al esencialismo a partir de la experiencia política reivindicativa de las comunidades afrocolombianas, preguntándose, "¿no es una forma de socavar y desempoderar los movimientos sociales y las comunidades étnicas?” (227). O Aura Cumes, quien, desde dicha noción, reconoce el valor de estas apuestas primordialistas y cosmovisionarias mayas para encontrar una voz propia, sin perder de vista el riesgo de reproducir absolutismos que impidan reconocer la pluralidad de propuestas y epistemes posibles (“"Esencialismos”68). 
"pensamiento propio" (Paredes s/i), "epistemologías indígenas" (Cumes, "Un patriarcado") o "afroepistemología" (García 65), entre otras. Estas buscan subrayar la especificidad y potencia teórico-política de los pensamientos racializados, a la vez que visibilizar la particularidad y limitaciones de los discursos enunciados falazmente como universales. De aquí la conveniencia de articular las nociones de lugar de enunciación y trayectorias políticas e intelectuales, atendiendo al hecho de que dicho lugar no es unívoco o fijo, sino que se va construyendo en diálogo y disputa con sus determinaciones estructurales y circunstancias históricas particulares.

Siguiendo a la filósofa feminista afrobrasileńa Djamila Ribeiro, diremos que el lugar da fala o lugar de la enunciación se estructura no solo como un "locus social" de emisión discursiva, sino también como un "régimen de autorización discursiva"; es decir, de establecimiento de aquellas voces que son legitimadas, dignas de ser escuchadas, y las que no: "Hablar no se restringe al acto de emitir palabras, sino de poder existir. Pensamos [el] lugar de enunciación como una forma de refutar la historiografía tradicional y la jerarquización de saberes consecuente de la jerarquía social” (17). El lugar de enunciación aparece entonces como aquella dimensión ineludiblemente política del pensamiento, que permite visibilizar y disputar los procesos de clandestinización, violencia epistémica (Spivak 217) o borramiento (Espinosa-Miñoso 10), implícitos en los discursos universalizantes o pretendidamente neutros. En otras palabras, desnudar el carácter situado de todo pensamiento, constituyendo otra forma de "privilegio epistémico" (Cumes, "Esencialismos" 75), de potencial contrahegemónico y descolonizador. Una conceptualización que no deja de ser polémica al articularla con enfoques interseccionales, como observa la intelectual feminista afrodominicana Yuderkys Espinosa-Miñoso cuando revisa las paradojas del feminismo crítico al reproducir "una práctica epistemológica que insiste convenientemente en borrar el lugar de enunciación privilegiada de las productoras del saber sobre las mujeres" (10). O al situar esta crítica en perspectiva con la propuesta de la filósofa de la ciencia y feminista estadounidense Sandra Harding respecto a la paradójica idea de "una" epistemología o "punto de vista" feminista, cuyo supuesto es la homogeneización y universalización de "lo" científico, "lo" moderno y "lo" androcéntrico, cuando las teorías feministas justamente apelan a la necesidad de pluralizar sentidos, 
discursos y experiencias (142-146). No obstante, hablamos de lugares de enunciación racializados como procesos a la vez teóricos, políticos y estéticos de reapropiación, resignificación y disputa, que en su propia configuración van evidenciando esas tensiones y paradojas. De ahí su potencia como ruta de aproximación.

Desde esta complejidad, cuando digo "mujeres racializadas" para situar desde una perspectiva amplia los pensamientos críticos desarrollados por intelectuales indígenas y afrodescendientes contemporáneas, estoy articulando los conceptos de "raza" y "racialización" con la categoría teórico-política de "mujer", comprendida desde el feminismo materialista de Silvia Federici, es decir, con la categoría de clase social. Esta aproximación permite visibilizar un rol socialmente construido, productivo y reproductivo de fuerza de trabajo no remunerada, forzada o explotada, que ha sido invisibilizado, privatizado y naturalizado desde el origen de la acumulación capitalista hasta nuestros días, tanto social como intelectualmente. Ello incluye la sexualización de mujeres racializadas desde el periodo colonial, en su papel de "domésticas", sirvientas, criadas, mães negras, amas de pecho, "chinas" e iniciadoras, esclavas o inquilinas sexuales. Una aproximación que no elude las consideraciones sobre el carácter reduccionista de la distinción binaria "hombre"/“mujer", sino que, al contrario, permite situar críticamente esa binarización, reconociendo la "imbricación de opresiones" (Curiel cit. en Barroso 17-18) que habitan mujeres y disidencias racializadas en Nuestra América.

Este espinoso debate permite plantear las preguntas que orientan nuestro recorrido: ¿cuál es el contexto de producción textual en que Lélia Gonzalez y Alicia Camacho configuraron sus particulares lugares de enunciación durante la década de 1980? ¿Desde qué producciones textuales podemos reconocer algunas de sus principales temáticas y giros políticos, intelectuales e identitarios en los ochenta? ¿Qué relevancia tienen la religión, el folclor, la militancia de izquierda, el movimiento negro, la academia y el feminismo en la construcción de sus pensamientos racializados? ¿Y cuál es la relevancia de sus obras y pensamientos? 
Paradojas DE FIN DE Siglo Y TENSIONES EN LOS CONTEXTOS DE PRODUCCIÓN

La patria se desangra, en los campos y en ciudad. Que se respete la vida, y el derecho a protestar...

Alicia Camacho, 1987.

La década de 1980 transcurre en plena instalación del neoliberalismo, la fase actual de acumulación capitalista ${ }^{3}$, establecida en la región a partir del violento desmembramiento de las izquierdas tradicionales, como excusa para el avance de procesos de modernización, y que, al calor del fin de la Guerra Fría, configura un nuevo paradigma neocolonial en las narrativas sobre lo nacional: el multiculturalismo estatal (Zapata 80-81) como forma predominante de inclusión simbólica de la diversidad cultural otrora negada, aun cuando persistan las condiciones de desigualdad estructural, minorización, discriminación racial y dominación patriarcal (Rivera Cusicanqui, Violencias 210-211). Y es que, paradójicamente, pese a toda la violencia sobre los cuerpos, territorios, organizaciones, comunidades y saberes populares -particularmente de mujeres racializadas-, la década de 1980 está caracterizada por un intenso proceso organizativo continental que irrumpe en la arena pública hacia 1990 con la campaña "500 años de Resistencia Indígena, Negra y Popular", poniendo en cuestión las bases coloniales del orden estatal republicano latinoamericano. Un movimiento que fuerza el nuevo paradigma multicultural con la "emergencia indígena" contemporánea ${ }^{4}$, un "espejo de la sociedad latinoamericana donde ésta se ve deformada" (Bengoa 12). Y que, en el caso de las comunidades y organizaciones negras, se articuló a nivel regional desde finales de los años setenta, a partir de los Congresos de la Cultura Negra de las Américas -con la presencia intelectuales de enorme relevancia, como el afrocolombiano Manuel Zapata Olivella o el afrobrasileño Abdías do Nascimento-, donde se denunció la opresión histórica del "hombre negro", se marca-

3 Esta fase incluye procesos de contrarreforma agraria, privatización de áreas de propiedad social, desregulación de mercados, restricción (o supresión) de derechos laborales y sindicales, y feminización creciente de la precarización de la vida, tanto en espacios sociales productivos como reproductivos.

4 En un marco de globalización, intensificación de las migraciones campo-ciudad y ampliación del acceso a educación formal de vastos sectores populares. 
ron posiciones antirracistas y antiimperialistas y se adoptó una nueva nomenclatura identitaria a partir de la noción de "afrodescendiente"

Hacia finales de siglo, se volvía evidente que la clase social había operado como una narrativa binaria de la desigualdad social (elite/pueblo), que, si bien permitió construir horizontes emancipatorios impensados frente al orden oligárquico y sus ambivalencias (Faletto 7-10), también operó como eficaz dispositivo de clandestinización de una heterogeneidad de condiciones, subjetividades, discursos, corporalidades y formas de organización, no reductibles a la cuestión de la clase. En el mundo afrodescendiente, ello provocó un desencantamiento de las narrativas de izquierda, como evidencia el intelectual afrodominicano Agustín Lao-Montes en su análisis de los años setenta y ochenta:

Muchos de los líderes de los movimientos negros en la región fueron parte de la izquierda latinoamericana pero eventualmente se sintieron desilusionados con el racismo y el reduccionismo de clase de la izquierda blanco/mestiza, y por ende realizaron cambios en su identidad política (222).

Una crisis que también se expresa en las incipientes políticas institucionales, tanto estatales como supraestatales, del multiculturalismo y su estrategia de reconocimiento a estas "mayorías con conciencia de minorías" (Rivera Cusicanqui, Violencias 211), como sucede en la Primera Conferencia Mundial sobre la Mujer -realizada en México el año 1975- a partir de la cual se proclama el ciclo 1975-1985 como "Decenio de las Naciones Unidas para la Mujer", imponiendo un feminismo liberal, eurocéntrico y hegemónico, que invisibiliza el proceso de la expansión y diversificación del movimiento de liberación de las mujeres "nuestroamericanas" (Gargallo 597-602).

¿Cómo se configuraron estas tensiones en los contextos de producción específicos de Lélia Gonzalez y Alicia Camacho? Un primer contrapunto lo encontramos en las propias experiencias nacionales: Brasil está en plena dictadura militar y, pese a que ha desarticulado buena parte de los movimientos y organizaciones sociales negras y populares en general (Gonzalez, Primavera 142), no renuncia al mito fundacional republicano de la pretendida democracia racial consagrada en obras clásicas como la de 
Gilberto Freyre. Una mistificación que envuelve el siglo XX a contrapelo de las comunidades racializadas, como la propia Lélia titula en uno de sus ensayos de 1981, “Democracia racial? Nada disso!”, donde denuncia las falacias de este ideario, junto a las del mito da mulata (de la "mujer fácil", "buena para la cama"), y de la supuesta "docilidad" del negro para adaptarse a la esclavitud del "amable" y "cordial" del amo luso-brasileño (Gonzalez, Primavera 111) ${ }^{6}$. Colombia, por su parte-marcada por el signo de su largo y complejo conflicto armado (Molano 5-6)-, en los años ochenta vive uno de los periodos más violentos del siglo (Marín), tanto por el nivel de organización armada, como por la enorme adhesión popular que logró el proyecto político de la Unión Patriótica (1985), un frente que aglutinó a sectores de la izquierda y desmovilizados de la guerrilla, y que fue masacrado por grupos paramilitares, agentes estatales y sicarios vinculados al narco, como se evidencia en el crudo documental de Yesid Campos, El baile rojo: memoria de los silenciados. Una década desgarradora, como escribe Camacho en su composición de 1987, "Colombia pide paz": "La patria se desangra / y ya no soporta más / el hambre y la miseria / ya quieren vivir en paz. / ¿Que haya paz, que haya paz! / en los campos y en ciudad".

Se trata de un momento geopolítico intrincado y perverso en que la intervención imperialista sobre América Latina parecía no tener límites. Sin embargo, es también un tiempo en que las marcas del multiculturalismo se expresan tempranamente en ambos países; hacia el final de la década, luego de intensos procesos constituyentes, promulgan dos nuevas constituciones, la de 1988 en Brasil y la de 1991 en Colombia, que aparecen como las más progresistas de la región, al presentarse como garantes de derechos colectivos - pese a servir de base para la expansión de políticas neoliberales en la década siguiente-. En estos procesos, ambas autoras muestran un activo compromiso. Lélia, como intelectual orgánica, crítica y articuladora de una serie de organizaciones determinantes para la época en la política nacional brasileña, como el Movimiento Negro Unificado, el Instituto de Investigación de las Culturas Negras, el feminismo negro brasileño $^{7}$ (donde funda el Colectivo de Mujeres Negras N'Zinga) y el

6 Narrativas que vuelven al racismo un tabú y al blanqueamiento (embranquecimento) una ideología dominante (De Andrade).

7 Donde fue pionera en las reflexiones simbólicas y estructurales que articulan raza, sexo y clase, junto a intelectuales negras contemporáneas responsables de “'ennegrecer' la agenda del movimiento feminista y 'sexualizar' la del movimiento 
propio Partido de los Trabajadores, del que fue candidata a diputada federal y electa como primera suplente (Santo Viana 107). Y Alicia, como militante del Partido Comunista, colaboradora de base del Movimiento 19 de abril (M-19), activista del proceso de la Unión Patriótica y comprometida folclorista con las músicas tradicionales de la marimba, el canto negro del litoral Pacífico y la canción protesta (Ardito 22-23). Ello, aun cuando ambas desarrollaron visiones sumamente críticas de la democracia que se gestaba en sus respectivos contextos.

Se evidencian así algunas de las particularidades de sus distintos ámbitos de producción: la academia comprometida y el folclor militante, respectivamente. Ámbitos que también pueden ser leídos como marcadores de sus diferentes territorialidades. En el caso de Lélia Gonzalez, la ciudad de Río de Janeiro, capital del Brasil imperial y de la era republicana hasta la década de 1960, polo de atracción migratorio (fundamentalmente del nordeste brasileño), espacio de síntesis e irradiación de una cultura popular afrobrasileña de alcance nacional desde la década de 1930 (Vianna 127), y cuna de vanguardias artísticas, como el Teatro Experimental Negro, desde los años cuarenta. Un territorio cosmopolita, profundamente marcado por la segregación social y racial. En el caso de Alicia Camacho, el puerto de San Buenaventura, principal terminal portuario colombiano desde mediados del siglo pasado, polo migratorio de comunidades negras rurales y ribereñas de la región Pacífica y cuna de las primeras plataformas organizativas nacionales de las comunidades negras en los ochenta -como el Movimiento Nacional Cimarrón (Grueso 60)-. Este lugar estaba fuertemente influido por las dinámicas de las diversas iglesias (incluyendo el determinante influjo de la Teología de la Liberación y la creación de la primera comunidad afrocolombiana musulmana en torno a la Nación del Islam). No obstante, era también uno de los territorios más abandonados, empobrecidos, violentos y militarizados del país desde los años ochenta, por su posición estratégica en el conflicto armado y el negocio del narco. Un puerto principal a la sombra de la ciudad interior de Cali, sin universidad, pero con una intensa actividad folclórica y cultural.

negro" (De Melo), tales como Sueli Carneiro y Thereza Santos. Si bien existen antecedentes de estas reflexiones desde la década del treinta, con grupos de mujeres que debatían su condición al interior del Frente Negra Brasileira, en esta época el movimiento alcanza una maduración teórica y organizativa sin precedentes, destacando el primer Encontro Nacional de Mulheres Negras (1988). 
Resulta curioso entonces que, póstumamente, el legado intelectual, político y cultural de ambas quede albergado en manos cruzadas: los escritos y entrevistas de Lélia, principalmente entre el movimiento negro y el candomblé de Ilê Oxum Apará (Uribe s/i); las composiciones y testimonios de Alicia, entre la custodia de su hijo y una serie de proyectos académicos independientes o vinculados a instituciones no colombianas, como la Universidad Andina Simón Bolívar o la Universidad de Boston.

\section{OBRA y CORPUS}

Eu falei de um passado africano, passado este que é desconhecido absolutamente...

Lélia Gonzalez, 1988.

Situados estos contextos radicalmente distintos de producción, podemos comprender algunas de las particularidades de las obras de ambas autoras que, como se ha seńalado, es mayoritariamente producida en la década de 1980. El pensamiento de Lélia Gonzalez se aloja en cerca de cincuenta ensayos y artículos académicos, políticos y de divulgación, así como en dos libros - uno en coautoría con el sociólogo argentino Carlos Hasenbalg, Lugar de negro (1982), y otro junto a 103 imágenes de destacados fotógrafos brasileños, Festas populares no Brasil (1988), que le valió la obtención de los premios Anuário do Clube de Criação de São Paulo (1988) y Leipzig (1989), dado a "os mais belos livros do mundo"-. Su obra también comprende entrevistas -escritas y audiovisuales-, que en los últimos años han sido publicadas en diversas plataformas digitales, o utilizadas como referencia para numerosos artículos, reseñas, tesis de grado y otros soportes de estudio y difusión de su pensamiento racializado. Una obra que hasta hace poco permaneció dispersa y que, gracias a recientes proyectos compilatorios, ha podido reconocerse como un conjunto, como sucede con Hospedando Lélia Gonzalez (2019) del Centro de Documentación de EAV Parque Lage ${ }^{8}$, donde Lélia fundó e impartió el primer curso de cultura

8 Un proyecto que alberga parte de las publicaciones y materiales recolectados por la autora, junto a la creación visual de estudiantes de la escuela libre EAV Parque Lage, en torno a su obra. 
negra del país, en plena dictadura militar (1976-1979). También ha contribuido enormemente a su reconocimiento la reciente publicación del libro Lélia Gonzalez em primeira pessoa. Primavera para as rosas negras (2018), una amplia compilación de artículos, ensayos, notas periodísticas y entrevistas escritas, desarrollado por la União dos Colectivos Pan-Africanistas de Sáo Paulo. Este volumen representa una contribución inédita para acceder a la obra reunida de la autora.

El pensamiento de Alicia Camacho, por su parte, se encuentra plasmado en más de una veintena de canciones de su autoría, en las que fusiona ritmos tradicionales de las músicas de marimba de chonta ${ }^{9}$ -jugas, bundes, arrullos, alabaos, bambucos viejos y currulaos, la danza madre del Pacífico colombiano-, con expresiones contemporáneas como la rumba y los lamentos. Se trata de una obra dispersa, que no fue grabada en su totalidad ${ }^{10}$, mas sí interpretada intensamente en escenarios folclóricos y políticos de la región -en uno de los cuales obtuvo el premio a la Canción Mensaje con su composición "Lamento porteño", en el Festival VOZ de Jamundí (1985), que organizaba el Partido Comunista-. Estas composiciones de los años ochenta y noventa fueron registradas en diversas entrevistas testimoniales que dio durante sus últimos años de vida a investigadores de distintas territorialidades con interés en conocer aspectos de la vida y obra de su maestro Teófilo Roberto Potes ${ }^{11}$, del islam en Buenaventura o del folclor negro del Pacífico. Alicia tenía la costumbre de narrar cantando sus

9 El denominado "piano de la selva del Pacífico sur colombiano", descendiente del balafón africano. Instrumento de percusión melódica con teclas de madera y resonadores de bambú o guadua (en el caso de la marimba de chonta) y calabaza (en el caso del balafón), capaces de emitir un sublime sonido de agua.

10 En más de una oportunidad fue escamoteada por querer grabar algunas de sus letras más polémicas. Quienes produjeron de los proyectos fonográficos en los que logró registrar su música (una grabación inédita realizada en 2005 y el disco compilatorio "Pacíficamente" de 2009), optaron por su repertorio menos político.

11 Reconocido folclorista de la región Pacífica, por su labor de sistematización y divulgación (fue el primero en organizar las expresiones tradicionales de la región para escenario). Sin embargo, como en el caso de Alicia, se trata de una figura intelectualmente invisibilizada, pese a la potencia y singularidad de su pensamiento comprometido con la valorización del legado cultural africano, el sentido político del folclor y la radical horizontalidad entre lo occidental y lo afropacífico (Birenbaum 113-115). 
canciones (como también hacía Lélia en sus discursos públicos, según recuerdan sus contemporáneos), por el profundo sentido testimonial de las mismas, lo que hace de estos registros un valioso y disperso reservorio, que ha podido compilarse y difundirse en los últimos años a través del proyecto web independiente La Caracola, donde también se alojan algunas de sus letras, digitalizadas por la autora junto a su hijo Mauricio Fidel Camacho ${ }^{12}$.

El repertorio temático que atraviesan estas dos obras es sumamente diverso: cultura, religión, academia -negra y occidental-, movimientos sociales, democracia, despojo, violencia, esclavitud, racismo, corrupción, feminismo -en el caso de Lélia-, entre otras. No obstante, enfocaremos la mirada en un cúmulo acotado, que permita reconocer aspectos clave de dos pensamientos racializados en contrapunto; ese diálogo de voces distintas que alternan su actuación en un mismo espacio sonoro, para generar una musicalidad conjunta -como hemos venido haciendo en estas páginas-, siguiendo la propuesta desarrollada en 1940 por el etnólogo y antropólogo cubano Fernando Ortiz, en su clásico ensayo Contrapunteo cubano del tabaco y el azúcar.

Comprendiendo que toda selección constituye una operación subjetiva de ponderación y recorte, el corpus se configura a partir de textos cuyos discursos representan marcas significativas de los principales giros intelectuales, políticos, estéticos e identitarios de sus respectivos lugares de enunciación. Para el caso de Lélia Gonzalez, tomaremos como base la entrevista testimonial "Lélia Gonzalez: Depoimento" (1980), identificando desde ahí algunos de los giros y textos con que esta dialoga. Y respecto de Alicia Camacho, se considerarán las composiciones "Río Tapaje" (1983), "El muelle se terminó" (1985), "Lamento porteño" (1985), "El Despertar de mi pueblo" (1988), "Descendiente africano" (1988) y "450 años" (1990), junto a algunas de sus reflexiones testimoniales sobre tales composiciones. 
TRAYeCtorias en CONTRAPUnto

\author{
En 1517, nos arrancaron del Africa \\ Y nos trajeron a América. Y fuimos esclavizados... \\ Alicia Camacho, 1988.
}

La gente nace negra, mulata, parda, marrón, rojita entre otras, pero convertirse en negra, es una conquista. Lélia Gonzalez, 1988.

Tanto Lélia como Alicia entran a la década de 1980 habiendo vivido procesos de transformación identitaria, política e intelectual muy profundos. Es interesante observar cómo, durante toda su producción textual del periodo, sus obras sintetizan tales transformaciones, siendo este, tal vez, uno de los elementos más determinantes para comprender la particularidad y potencia de sus pensamientos. Ambas son autoras que piensan reconociendo sus contradicciones -tanto personales como colectivas-, observando los procesos políticos y culturales del pueblo negro del que se sienten parte y de la sociedad mayor en que se insertan. Lélia Gonzalez, actuando como una intelectual orgánica del movimiento negro brasileño, de la izquierda política y del feminismo negro, al tiempo que como una mujer afrobrasileña cada vez más próxima al culto de los terreiros de candomblé o macumba (Lima 176); y Alicia Camacho como una folclorista de trinchera, comprometida cultural y políticamente con los procesos organizativos y reivindicativos del pueblo negro litoraleńo, y como una activa integrante de la comunidad musulmana de Buenaventura, siendo la primera mujer afrocolombiana en convertirse al islam (Vigón). No obstante, este no siempre fue el lugar de enunciación desde el que situaron sus reflexiones.

Nacida en una familia pobre de Belo Horizonte, hija de un "operário negro" y de una "índia analfabeta", Lélia fue la única de sus dieciocho hermanos en acceder a la universidad, logrando desempeñarse como docente y académica, un proceso que en esta década tematiza como un "lavado cerebral dado por el discurso pedagógico-brasileño", emblanquecida y cada vez más alejada de su "condição de negra" (Primavera 82): 
$\mathrm{Na}$ faculdade eu já era uma pessoa de $\mathrm{cuca}^{13}$, perfeitamente embranquecida, dentro do sistema [...] Cuando chegou a hora de casar, eu foi casar com un cara branco [...] Estava reprimido, todo un processo de internalização de um discurso 'democratico racial' [...] eu usava peruca, esticava o cabelo, gostaba de andar vestida como uma lady (Primavera 82-83).
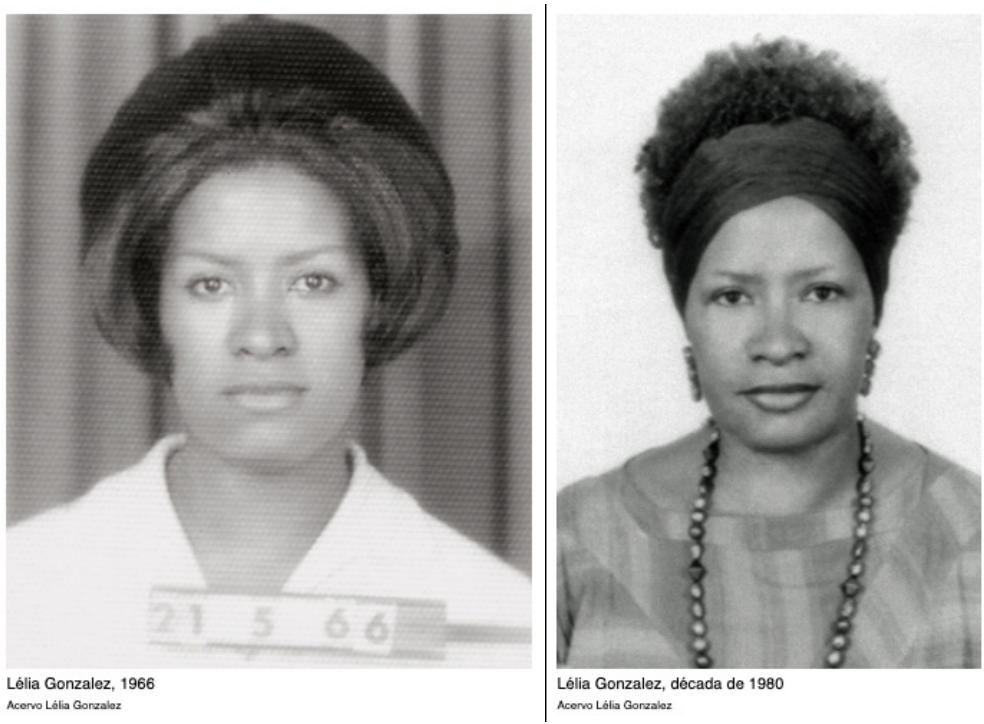

Imagen 1 (izq.): Lélia Gonzalez en 1966. Imagen 2 (dcha.): Lélia en la década de 1980.

(Acervo Lélia Gonzalez. Projeto Memoria: http://www.projetomemoria.art. $\mathrm{br} /$ leliaGonzalez)

Lélia se tornó "Gonzalez" (De Andrade 19) tras el suicidio de su primer marido, Luiz Carlos Gonzalez, hostigado por su familia a causa de haberse casado con una mujer "negra" y, por tanto, "sucia", "prostituta”. Pues, como señala Fanon, "una mujer de color nunca es totalmente respetable a los ojos de un blanco" (65-66). Una experiencia de racismo y discriminación que pesquisó largamente en sus escritos posteriores, en un ejercicio teórico, político y estético que le permitió el paso del 
"yo" al "nosotras"; deconstruyendo, desde el psicoanálisis ${ }^{14}$, el mito da mulata, como realiza en los escritos "Democracia racial? Nada disso!" y "Mulher negra, essa quilombola", ambos de 1981.

Desde acá, la autora inicia todo un proceso de "ennegrecimiento" (Carneiro 5), reconociendo en las expresiones folclóricas y en general populares, espacios de descolonización de la beleza negra -como se aprecia en su artículo "Beleza negra, ou: ora-yê-yê-ô!", de 1982-, y hurgando en las causas históricas y económicas de ese racismo, desde una mirada materialista, en textos como "A mulher negra na sociedade brasileira. Uma abordajem político-econômica", de 1981, y "E a trabalhadora negra, cumé que fica?", de 1982. De esa forma actualizaba un debate histórico y económico sobre el papel de la esclavitud colonial en el desarrollo del capitalismo global, iniciado en buena medida por el trabajo del intelectual y político afrotrinitense Eric Williams, desde una perspectiva feminista. El estudio histórico profundizó su conciencia como "mulher negra", mientras el universo del candomblé la aproximó a su ancestralidad africana desde la espiritualidad, la ritualidad colectiva y el compromiso social comunitario (Santo Viana 71-73), superando su propio desprecio. Como señala la propia Lélia: "Manifestaçóes culturais que eu, afinal de contas, com uma formacáo em Filosofia, transando uma forma ocidental táo sofisticada, claro que no podia olhar como coisas importantes" (Primavera 83).

La autora logró desarrollar entonces una visión política del folclor, lejos de las miradas esencializantes producidas desde la "academia occidental". "Tais análises são responsáveis pela 'folclorizacáo' das nossas manifestaçóes folclóricas, populares" (15), plasmaba en su premiado Festas populares no Brasil, hacia finales del periodo, pues para ella se trataba de espacios de resistencia histórica y adaptación estratégica. Un punto en que su trayectoria se teje con los giros que van configurando el lugar da fala de Alicia.

Cantadora por necesidad, inquieta y militante desde temprana edad, Alicia cantaba boleros, rancheras, pasodobles y contradanzas cuando conoció a quien se convertiría en su maestro, Teófilo Roberto Potes,

14 Que había conocido como parte de la instalación del Colegio Freudeano de orientación lacaneana en Río. 
al escuchar su programa radial de divulgación y educación popular negra El Conjuro de las Estrellas, un espacio que la cautivó ante la curiosidad que sentía por indagar en su pasado histórico:

Uno oía hablar de África, pero como una cosa lejana; que vivían en los árboles, que eran ignorantes. Entonces yo me hice el propósito de investigar mi pasado cultural [...] y saber si era verdad que eran ignorantes, que eran animales [...] Yo iba más que nada tras de los lamentos [...] sentía la necesidad de investigar mi pasado histórico y a la vez sentía la música, pues nuestra gente tiene la costumbre de cantar (Ardito, "Entrevista").

A diferencia de Lélia, quien transitó desde la academia hacia el candomblé, Alicia pasó de la música popular al folclor-descubriendo un espacio profundamente político de resistencia histórica con el que había convivido desde muy pequeña-. Y desde ahí, al islam, espacios determinantes en su propia elaboración de un "nosotros negro":

Cuando voy adquiriendo todo ese conocimiento de Teófilo es que me pongo a pensar, y por todo lo que yo discutía con él, que la lucha no era a nivel del Partido Comunista, por los problemas raciales que había también. Que a pesar de que hablaban de una lucha de clases, había discriminación. Entonces me pongo a pensar que la lucha tiene que ser, para nosotros los negros, a través del islam. Y ahí fue que yo salgo a buscar la gente que había estado en Buenaventura con el proceso islámico (Birenbaum, "Entrevista").

Alicia entra en la década de 1980 con estas experiencias encima, y tras la muerte de su maestro y compañero de lucha, comienza a componer su poética cimarrona (De Carvalho 35), como se aprecia desde sus primeras composiciones, en las que el "yo" resuena junto a la idea de "raza", como un lugar de reivindicación marcadamente panafricano:

Ay, río Tapaje llévame

Ay, rio Tapaje me voy

Voy buscando los ancestros

de mi origen africano 


\section{Llego al Charco Campoalegre \\ la capilla El Hormiguero}

Porque aqui en rí Tapaje

nació mi taita y mi mama

Vengo en busca de la juga

el bunde y el currulao

Estas tierras olvidadas

del gobierno colombiano

Solo explotan sus maderas

para las grandes empresas.

Yo me siento orgullosa

de mi tierra tapajeña

Porque aqui quedó sembrado

el pasado de mi raza...

("Río Tapaje", 1983)
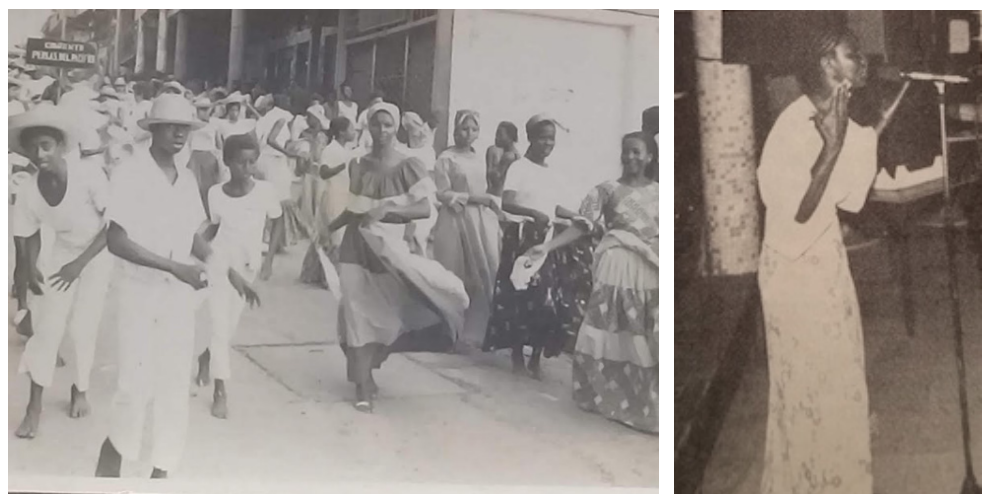

IMAGEN 3 (izq.): Alicia Camacho en la década de 1960.

IMAGEN 4 (dcha.): Alicia cantando en 1985.

(Archivo familiar de Mauricio Fidel Camacho). 
Otro aspecto que resalta en la obra de ambas autoras durante los ochenta, y que vislumbra posiciones difícilmente etiquetables respecto de las sociedades de su tiempo, tiene que ver con la forma en que se sitúan dentro de sus respectivas militancias. En el caso de Lélia, se trata de un lugar profundamente crítico, constructivo y confrontacional, que plasmó en sus escritos sobre la izquierda brasileńa y el movimiento de mujeres desde un "nosotros negro", señalando, como punto de partida, "eu pertenezo ao Movimento Negro Unificado" (Primavera 84). La autora revisó la particular forma de racismo de los sectores progresistas, en ensayos como "Racismo por Omissão", de 1983, cuidándose de realizar un examen agudo sobre aquello que Spivak denominó "violencia epistémica" (317-321), sin caer en la tentación de realizar generalizaciones y llamando con vehemencia a la toma de conciencia. Del mismo modo, criticó el "esquecimento da questão racial" en las prácticas y teorías críticas del feminismo (Primavera 307). Y en sus análisis del propio movimiento negro -"O Movimento Negro na Última Decada", de 1982-, como de las organizaciones del feminismo negro - "A importáncia da organizão da mulher negra no processo de transformação social", de 1988-, dio cuenta tanto de la diversidad de esos "nosotros" y "nosotras" en gestación -incluyendo la reflexión sobre las disidencias en "Mulher Negra: Um retrato" de 1979-, como de la relevancia de encontrar una orgánica y un discurso común contra el racismo y el sexismo dentro y fuera de la organización, problemáticas que lee como efecto "da internacionalização da ideologia do embranquecimento, que remetem a oportunismos e manipulações típicos do velho paternalismo eurocêntrico das oligarquias brasileiras" (Primavera 364). Nos remite a ese lugar intersticial y ambivalente del que habla Harding cuando analiza los feminismos del punto de vista (142-143), pero no desde la identificación parcial o inconforme, sino siendo plenamente actuante dentro y fuera de sus militancias de izquierda, negra, antirracista y feminista.

En el caso de Alicia, esta posición se marca en sus testimonios como un llamado permanente a la toma de conciencia de la manipulación y explotación del "blanco del interior al negro litoraleńo", o "del propio negro hacia su gente" (Birenbaum, "Entrevista"), que hace eco de la propuesta descolonizadora de Fanon en Piel negra, máscaras blancas. En estas elaboraciones, la autora adopta diversas estrategias retóricas para construir su lugar de enunciación: utiliza una voz omnisciente y lejana para otorgar al pueblo de Buenaventura el papel de sujeto histórico des- 
pojado y alienado -"El muelle se terminó", escrito en 1985, durante el proceso de privatización de Colpuertos-, pero también al "yo" racializado con plena conciencia del "nosotros" que enuncia y denuncia -"Lamento porteño”, de 1985-, como se aprecia en los siguientes fragmentos:

\author{
El pueblo de Buenaventura \\ No sabe lo que ha pasado \\ Que este terminal de aqui \\ Ya casi está acabado
}

Ay, Buenaventura

El muelle se terminó

Ay, Buenaventura

El litoral se acabó

Ay, Buenaventura

Sin muelle ya se quedó

(“El Muelle se terminó” 1985. Transcripción de Arboleda 355-356)

Del puerto de Buenaventura

Yo les vengo hoy a cantar

Les traigo este canto negro

Del fondo del litoral

Ay, Buenaventura

Mi litoral

Buenaventura está triste

Está cansado de sufrir

De recibir las migajas

Qué nos dan del interior?

Se llevan de nuestros mares

Camarones y pescados

Se llevan los langostinos

$Y$ también nuestra madera 


\section{Al gobierno colombiano \\ Yo le vengo a preguntar \\ Si no tenemos derecho \\ A que nos den universidad}

Se mueve por nuestros muelles

La riqueza colombiana

$Y$ a nosotros que nos queda

El descrédito y la miseria

\section{Al gobierno colombiano \\ Yo le vengo a preguntar \\ Si no somos colombianos \\ $Y$ todito el litoral}

(“Lamento porteño" 1984. Trascripción de Arboleda 353-354)

Una denuncia en que aparece la conciencia geopolítica, materialista y ciudadana de la autora, frente al abandono del pueblo negro litoraleño en el proyecto nacional colombiano. Esto nos sirve de puente para destacar un último elemento significativo en el lugar de enunciación que ambas autoras construyen y plasman muy claramente hacia el final de esta década: la perspectiva afrodiaspórica latinoamericana, que, en términos de Lélia, podríamos simplemente llamar "amefricana":

[A] categoría da Amefricanidade incorpora todo um processo histórico de intensa dinâmica cultural (adaptação, resistência, reinterpretação e criação de novas formas) que é afrocentrada [...]. Seu valor metodológico, a meu ver, está no fato de permitir a possibilidade de resgatar uma unidade específica, historicamente forjada no interior de diferentes sociedades que formaram uma determinada parte do mundo. Portanto, Améfrica, encuanto sistema etno-geográfico de referência, é uma criação nossa e de nossos antepassados no continente em que vivemos, inspirados em modelos africanos (Primavera 329-330).

"Améfrica Ladina" es una categoría enunciada en los ámbitos de estudios sobre psicoanálisis en que Lélia participaba, que exploró desde la ironía y la creatividad y que le permitió, además, pensar a Brasil desde 
esa amefricanidade, donde tematizó el racismo como "neurosis brasileña" y el pretugués $^{15}$, como marca de aquella herencia negra negada, reprimida, explotada, racializada, sexualizada, de dimensiones simbólicas, aunque impensables sin considerar el "genocidio" sistemático de la población negra. Una reflexión desde donde también surgió la posibilidad de pensar en "feminismos amefricanos", como horizontes emancipatorios amplios, diversos, a la vez específicos y regionales, y profundamente libertarios.

Para Alicia esta "conciencia amefricana" -o más precisamente "cimarrona", utilizando sus propias evocaciones textuales-, se expresa en varias de sus composiciones. No obstante, creo que sus elementos más significativos se manifiestan con claridad en tres de ellas.

"El Despertar de mi pueblo" (1988) es una canción alentadora que habla de la organización popular frente a la corrupción de las elites negras de Buenaventura, la cual utiliza el apellido Carabalí como un juego para mostrar la continuidad histórica con las luchas cimarronas por la liberación afrolatinoamericana: "Por primera vez aquí, está unido mi pueblo / Alrededor de este hombre, llamado Carabalí / Los Carabalí son hombres, que habitaron los palenques / Despierta Buenaventura, defiende tu litoral" (La Caracola s/i).

También es relevante en este aspecto "Descendiente africano" (1988), en la cual aparece la mirada continental de la diáspora, desde una hermandad que nos recuerda su vínculo con la vertiente musulmana de la Nación del Islam: "En 1537 / Nos arrancaron del África / Y nos trajeron a América / Y fuimos esclavizados / Negro, negro, negro / Es mi hermano americano". (La Caracola s/i).

Finalmente "450 años”, en que la autora liga la problemática de Buenaventura con la historia de la esclavitud negra en América, feminizando el territorio e introduciendo una metáfora sobre las "carnes morenas" que nos recuerda el mito da mulata de Lélia, esta vez como expresión del despojo sobre la tierra y su gente negra:

\section{0 años de marginamiento}

450 años de marginación

15 Neologismo enunciado por la autora para evidenciar la marca afrodiaspórica en la lengua oficial brasileña, pretendida como extensión de la matriz luso-europea, cuando en su rica expresión hablada está profundamente permeada por expresiones de origen africano e indoamericano. 


\section{Eres Buenaventura \\ Reina en tu hermosura \\ Eres la capital morena \\ De este litoral}

De tus carnes morenas

Muchos se han servido

Luego en el olvido

Todito quedó

(“450 años” 1990. Transcripción propia a partir

de audio publicadoen La caracola s/i)

\section{VALORACIÓN DE LAS AUTORAS Y SUS OBRAS}

Si recordamos el carácter de "régimen de autorización discursiva" (Ribeiro 14) que representa el lugar de enunciación -en la medida en que permite reconocer el estatus de legitimidad de las autorías estudiadas-, creo entonces relevante concluir este recorrido con la pregunta por la valoración de las autoras y sus obras.

La historiadora feminista afrobrasileña Elizabeth Santo Viana, quien fuera estudiante de la maestra Lélia Gonzalez en un mundo universitario que continúa teniendo escasísima presencia negra, señala que su pensamiento se ha vuelto una referencia ineludible para los movimientos sociales brasileńos -negros, feministas y en general de izquierda-, pese a que quienes custodian su obra -familiares y amigos vinculados al candomblé-, esperan atentos la posibilidad de acceder a un financiamiento que permita su tratamiento archivístico adecuado y la fundación de un centro de estudios:

Sua contribuiçáo aos movimentos sociais e ao pensamento político contemporâneo é reconhecida não só por ativistas como por estudiosos da história recente do país. Assim, se insere entre intelectuais das décadas de 1970 e 80 que reconhecem "a conexão íntima e direta entre democracia política e democracia racial" (Santo Viana 44). 
Un reconocimiento que en vida fue consagrado con su participación en diversas instancias del feminismo crítico y la intelectualidad negra internacional, y que, póstumamente, fue acrecentado con la visita de la feminista afroestadounidense Angela Davis ${ }^{16}$ a Brasil en noviembre de 2019 -en el marco de las conmemoraciones del Día de la Conciencia Negra-, quien refirió en varias ocasiones la necesidad de que "el mundo conozca la obra de la brasileña" "Citada". No obstante, su reconocimiento sigue resultando escaso fuera de las militancias feministas antirracistas y afrodescendientes en Hispanoamérica.

En una posición radicalmente distinta, Alicia Camacho vivió un permanente proceso de clandestinización pública, siendo reconocida como una de las discípulas más próximas al legado intelectual y cultural del maestro Potes y una destacada folclorista (como bailarina, coreógrafa, cantadora y cantautora), mas invisibilizada como intelectual libertaria y comprometida en movilizar la conciencia del pueblo negro litoraleño. Sin embargo, trabajos como los de Santiago Arboleda ${ }^{17}$, permiten apreciar la lucidez de esta "artista pensadora" para leer tempranamente algunos de los procesos más críticos del neoliberalismo en Buenaventura (355), al tiempo que para crear, desde estas "otras formas", un completo "ideario político":

El canto y las letras de Camacho diagraman un verdadero manifiesto político y un ideario de anhelos, sueños, deseos y realizaciones posibles para el hombre y la mujer de esta región. Ideario que postula la necesidad de una justicia social en relación con lo que la región produce y aporta al resto de la nación (Arboleda 350).

16 Una de las principales referentes continentales y globales del feminismo negro, quien fuera militante del Partido Comunista estadounidense y las Panteras Negras, lo que le valió ser perseguida y presa política en los ańos setenta, cuando trabajaba como docente auxiliar de Filosofía en la Universidad de California, acusada de secuestro a un juez federal que trabajaba en el caso de los hermanos afroestadounidenses de la cárcel de Soledad. Este momento fue determinante tanto en la producción como en la recepción de su pensamiento crítico, pues la presión global de organizaciones y movimientos sociales volvieron imposible su condena.

17 Quien, en su estudio sobre la clandestinización pública y las "suficiencias íntimas" del pensamiento afrocolombiano durante el siglo xx, incluye la obra de Alicia Camacho Garcés como única voz femenina junto a otros nueve autores (Manuel Zapata Olivella, Arnoldo Palacios, Alfredo Vanín Romero, Luis Antonio Robles, Diego Luis Córdoba, Amir Smith Córdoba, Martín Silva Solís, Benildo Castillo y Teófilo Roberto Potes). 
En vida, el reconocimiento de su figura pública tuvo un retroceso. En el ámbito folclórico y militante, por su posición consecuente, radical y profundamente crítica no solo de la sociedad colombiana de su tiempo, sino en particular de las prácticas políticas y culturales locales del "hombre negro". Y, en el espacio religioso del islam en Buenaventura que integró desde los años sesenta, por la conversión chiita que vivió la comunidad musulmana en las últimas décadas, desplazando el papel político de las mujeres (Vigón).

Su valorización intelectual tardía viene dándose mayoritariamente a través de la divulgación de sus entrevistas testimoniales, mediante plataformas permanentes y abiertas de difusión, tales como The Alicia Camacho Garcés Project, de la Universidad de Boston, coordinado por el etnomusicólogo colombiano Michael Birenbaum, o el sitio web independiente La Caracola, coordinado por su hijo Mauricio Fidel Camacho, quien custodia de su precario y valioso acervo familiar.

REFLEXIONES AL CIERRE: CONCIENCIAS CIMARRONAS Y AMEFRICANAS EN PERSPECTIVA

Este breve contrapunto entre las trayectorias políticas e intelectuales de Lélia Gonzalez y Alicia Camacho evidencia cómo ni la visión sobre el folclor como un espacio esencializante, ni la mirada hacia la religión como lugar de institucionalización patriarcal atávica, permiten comprender en su totalidad la potencia política, estética e intelectual de sus singularidades. Del mismo modo que tampoco lo permite la crítica al machismo imperante en los movimientos negros antirracistas o indígenas anticoloniales.

Más allá de cualquier intento de clandestinización, encasillamiento o reducción a influencias externas, ambas tuvieron en la religión un espacio de autoafirmación y conciencia, en la militancia de izquierda una escuela permanente de formación y acción política -aun cuando sufrieron discriminación racial-, en el folclor un escenario de valoración de la diversidad, aprendizaje y resistencia histórica; en la academia una plataforma estratégica de divulgación, y en el movimiento negro -incluyendo al feminismo negro, en el caso de Lélia-, un refugio liberador desde el cual situar su voz como expresión de una lucha colectiva. Confluencias notables pues, como vimos, se trata de dos autoras sumamente distintas, 
tanto en sus contextos de producción, divulgación y valorización, como en sus legados culturales, políticos e intelectuales.

El recorrido expuesto evidencia las marcas de influencias religiosas, culturales, territoriales e intelectuales que no siempre resultan visibles desde la óptica teórico-política de los feminismos interseccionales y de(s)coloniales, ya que, en su afán por generar categorías abarcadoras que disputen terreno a los feminismos hegemónicos, acaban reduciendo nuestro campo de visión y enunciación. Paradójicamente, en tiempos en que los feminismos -incluso contrahegemónicos- tienen una presencia social y teórica inusitada, al volverse populares las nociones de "interseccionalidad" o "triple opresión" (Cumes, "Mujeres" 6), al dejar de explicarse en su complejidad, ambivalencia, diversidad y potencia, se vacían de sentido, se desvinculan de la lucha política, y quedan a merced de políticas estrechas y reproductoras del orden social, como las cuotas de inclusión con perspectiva de género e interculturalidad, o los propios discursos de las corrientes feministas liberales. Se trata de un secuestro que tiene un enorme peso.

En este contexto, la riqueza temática, biográfica, estética, teórica y poética de las autoras revisadas, nos recuerdan no solo la necesidad de (re)conocer las trayectorias "amefricanas" y "cimarronas" dentro y fuera de los pensamientos críticos nuestroamericanos, sino, además, la potencia, complejidad y relevancia de sus experiencias de opresión y reflexión crítica en la construcción de alternativas antirracistas y descolonizadoras desde Nuestra América y en los análisis y luchas por transformar las contradicciones de nuestro tiempo, desde horizontes más justos y plurales. 
BibLIOGRAFÍA

Abdala, Julia. Entrevista (audiovisual) realizada por Celso Loducca el 18 de febrero de 2020. Pensamento Descolonial: Lélia Gonzalez, por Julia Adballa, Série Pensamiento Descolonial, Brasil, 2020.

Arboleda, Santiago. Le han florecido nuevas estrellas al cielo: suficiencias intimas y clandestinización del pensamiento afrocolombiano. Tesis para optar al grado de Doctor en Estudios Culturales Latinoamericanos, Universidad Andina Simón Bolívar, Sede Ecuador, 2011.

Ardito, Lorena. "Incómoda Cimarrona. Alicia Camacho resonando entre la memoria, la palabra y la resistencia". La negritud y su poética: Prácticas artísticas y miradas críticas contemporáneas en Latinoamérica y España, Andrea Díaz (ed.), Montevideo, Acer-Vos / BMR, 2019, pp. 337-356.

"Entrevista a Alicia Camacho (audio)", realizada el 23 de enero de 2009. Ruta de Aprendizaje "Pasos, tones y sones", ACUA/ PROCASUR.

Barroso. José María. "Imbricación de las opresiones. Un camino para la transformación social desde la decolonialidad. Entrevista con Ochy Curiel”. Iberoamérica Social, s/i, 2017, pp. 12-18.

Bengoa, José. La emergencia indigena en América Latina. Santiago de Chile, FCE, 2000.

Birenbaum, Michael. "La audaz intelectualidad afro de Teófilo Potes". Revista CS, $\mathrm{N}^{\circ} 30,2020$, pp. 97-122.

. "Entrevista a Alicia Camacho (audio)", realizada el 28 de diciembre de 2013. Alicia Camacho Garcés Project. University of Boston. 28 de septiembre de 2020.

Camacho, Alicia. “¿Descubrimiento de qué?” (1992). Registro inédito, 2015.

. "El Despertar de mi pueblo" (1988). Transcripción, s/i. . "El muelle se terminó" (1985). Trascripción, 2011. . "Lamento porteño" (1984). Grabación inédita, 2014. "Río Tapaje" (1983). Grabación inédita, 2013.

Camacho, Alicia y Caracoles Cantores. 450 Años (1990). Registro inédito, XVIII Festival de Música del Pacífico Petronio Álvarez, 2014. 
. Colombia pide paz (1987). Grabación inédita, 2005. . Descendiente Africano (1988). Grabación inédita, 2009.

Campos, Yezid. El baile rojo. Memoria de los silenciados. CEICOS y GYC Comunicación, Colombia, 2003.

Carneiro, Sueli. "Ennegrecer o feminismo: a situacao da mulher negra na américa latina a partir de uma perspectiva de gênero". Negra cubana, 14 de enero de 2021. Web. https://edisciplinas.usp. br/pluginfile.php/375003/mod_resource/content/0/Carneiro_Feminismo\%20negro.pdf

"Citada por Angela Davis, pionera brasileña Lélia Gonzalez precisa ser renonhecida", Rede TVT, Brasil, 2019.

Cumes, Aura. "Mujeres indígenas, patriarcado y colonialismo: un desafío a la segregación comprensiva de las formas de dominio". Anuario Hojas de Warmi, N 17, 2012, pp. 1-17.

"'Esencialismos estratégicos' y discursos de descolonización". Más allá del feminismo: caminos para andar, Márgara Millán (coord.), Ciudad de México, Red de Feminismos Descoloniales, 2014, pp. 61-86.

. "Un patriarcado colonial somete no sólo a las mujeres". Entrevista realizada por Bárbara Barrera. Palabra Pública. 28 de julio de 2018. Universidad de Chile. 25 de septiembre de 2020. Web. https://palabrapublica.uchile.cl/2018/07/23/aura-cumes-escritora-un-patriarcado-colonial-somete-no-solo-a-las-mujeres/

Curiel, Ochy. La Red de Mujeres Afrolatinoamericanas y Afrocaribeñas: Un intento de acción politica transnacional atacado por la institucionalización (Documento de Trabajo). Ciudad de México, CEPI/ ITAM, 2006.

De Andrade, Raquel. Enegrecendo o Feminismo ou Feminizando a Raça: Narrativas de Libertação em Angela Davis e Lélia Gonzalez. Tesis para optar al grado de Mestre em História Social da Cultura, Departamento de História, Pontíficia Universidade Católica do Río de Janeiro, 2005.

De Carvalho, José. "Cimarronaje y afrocentricidad: los aportes de las culturas afroamericanas a la América Latina contemporánea”. Pensamiento Iberoamericano, $\mathrm{N}^{\circ}$ 4, 2009, pp. 25-47. 
De Melo, Rafaela. "Aportes del feminismo negro brasileño para la perspectiva interseccional”. XIII Jornadas de Sociología, Buenos Aires, Universidad de Buenos Aires, 2019.

EAV Parque Lage. Hospedando Lélia Gonzalez. Río de Janeiro, Biblioteca del Centro de Documentación de EAV Parque Lage, 2019.

Espinosa-Miñoso, Yuder KYs. "Una crítica descolonial a la epistemología feminista crítica”. El Cotidiano, N¹84, 2014, pp. 7-12.

Faletto, Enzo. La arquitectura como documento social: la ambigüedad de la modernidad. Versión inédita, 1999.

Fanon, Frantz. Piel negra, máscaras blancas. Madrid, Akal, 2009.

Freyre, Gilberto. Casa-Grande y Senzala. Caracas, Fundación Biblioteca Ayacucho, 1977.

Federici, Silvia. Calibán y la bruja. Mujeres, cuerpo y acumulación originaria. Madrid, Traficantes de sueños, 2010.

Gargallo, Francesca (ed.). Antología del Pensamiento feminista nuestroamericano. (Tomo II). Caracas, Biblioteca Ayacucho, 2010.

González Ortuño, Gabriela. "Los feminismos afro en Latinoamérica y El Caribe, tradiciones disidentes: del pensamiento anticolonial a la defensa del territorio". Investigaciones Feministas, № 2, 2019, pp. 239-254.

Gonzalez, Lélia. Festas populares no Brasil, Rolando Graça (coord.), Río de Janeiro, INDEX, 1989.

- Primavera para as rosas negras. Lélia Gonzalez em primeira pessoa. União dos Colectivos Pan-Africanistas (comp.), Río de Janeiro, Diáspora Africana, 2018.

Grueso, Libia. El proceso organizativo de comunidades negras en el Pacifico sur colombiano. Tesis para optar al grado de Magíster en Estudios Políticos, Programa de Maestría en Estudios Políticos, Facultad de Humanidades y Ciencias Sociales, Pontifica Universidad Javeriana, 2000.

Harding, Sandra. Ciencia y feminismo. Madrid, Morata, 1996.

Lao-Montes, Agustín. "Cartografías del campo político afrodescendiente en América Latina”. Universitas humanistica, N 68, 2009, pp. 208-245. 
Lima, Denilson. "El terreiro de candomblé representado en la poética de Aloísio Resende y Solano Trinidade". Cuadernos de Literatura del Caribe e Hispanoamérica, N²0, 2016, pp. 163-180.

Lugones, María. “Colonialidad y género”. Tábula Rasa, N9, 2008, pp. 73-101.

Marín, María Del Pilar. "Las violaciones de derechos humanos en Colombia durante los ańos 80 del siglo xx: acercamiento a su comprensión histórica desde la degradación y el fortalecimiento de la defensa". Anuario de Historia Regional y de las Fronteras, $\mathrm{N}^{\circ} 1$, 2017, pp. 113-135.

Martí, José. Nuestra América. Caracas, Fundación Biblioteca Ayacucho, 2005.

Molano, Alfredo. Fragmentos de la historia del conflicto armado (1920-2010). La Habana, Espacio Crítico, 2015.

Oliva, Elena. Intelectuales afrodescendientes de habla hispana: debates y trayectorias en el siglo XX latinoamericano. Tesis para optar al grado de Doctora en Estudios Latinoamericanos, Centro de Estudios Culturales Latinoamericanos, Facultad de Filosofía y Humanidades, Universidad de Chile, 2016.

Ortiz, Fernando. El engaño de las razas. La Habana, Fundación Fernando Ortiz, 2011.

Paredes, Julieta. "El Feminismo comunitario: la creación de un pensamiento propio". Corpus. Ardhivos Virtuales de la Alteridad Americana, $\mathrm{N}^{\circ} 1,2017$, s/i.

Quijano, Aníbal. “¿Qué tal raza?”. Ecuador Debate, No 48, 1999, pp. 141-151.

Quintanar, Daniela. Espacios de resistencia y permanencia cultural de las africanas libres en Santiago de Cuba en el siglo XIX. Tesis para optar al grado de Maestra en Estudios Latinoamericanos, Facultad de Filosofía y Letras, Universidad nacional Autónoma de México, 2017.

Restrepo, Eduardo. "Esencialismo étnico y movilización política: tensiones en las relaciones entre saber y poder". Gente negra en Colombia. Dinámicas sociopolíticas en Cali y el Pacifico. Olivier Barbary y Fernando Urrea (eds.), Medellín, Centro de Investigaciones y Documentación Socioeconómicas de la Universidad del Valle / 
CIDSE / L'Institute de Recherche pour le Développement (antes ORSTOM) / IRD / COLCIENCIAS, 2004, pp. 227-244.

Ribeiro, Djamila. "Breves reflexiones sobre Lugar de Enunciación". Relaciones Internacionales, N³9, 2018, pp. 13-18.

Rivera Cusicanqui, Silvia. Violencias (re)encubiertas en Bolivia. La Paz, La Mirada Salvaje / Piedra Rota, 2010.

. Sociología de la imagen. Miradas Ch'ixi desde la historia andina. Ciudad Autónoma de Buenos Aires, Tinta Limón, 2015.

Santo Viana, Elizabeth. Relaçóes raciais, gênero e movimentos sociais: o pensamento de Lélia Gonzalez, 1970-1990. Tesis para optar al grado de Mestre em História Comparada, Instituto de Filosofia e Ciências Sociais, Universidade Federal do Río de Janeiro, 2006.

Spivak, Gayatri. “'Puede hablar el subalterno?”. Nota Introductoria de Santiago Giraldo. Revista Colombiana de Antropología, N³9, 2003, pp. 297-364.

Tijoux, María Emilia y Simón Palominos. "Aproximaciones teóricas a estudio de los procesos de racialización y sexualización en los fenómenos migratorios de Chile". Polis. Revista Latinoamericana, $\mathrm{N}^{\circ} 42,2015$, pp. 247-275.

Uribe, Julio. "Lélia Gonzalez. Améfrica Ladina su patria, pretugués su lengua". El Guarengue. 26 de julio de 2019. 28 de septiembre de 2020. Web. https://miguarengue.blogspot.com/2019/07/lelia-gonzalez-amefrica-ladina-su.html

Vianna, Hermano. O Misterio do Samba. Río de Janeiro, Editora UFRJ, 1999.

Vigón, Mercedes, Islam in Buenaventura. International Media Center, Florida International University, EE. UU., 2014.

Wade, Peter. Raza y etnicidad en Latinoamérica. Quito, Abya Ayala, 2000.

Zapata, Claudia. Crisis del culturalismo en América Latina. Conflictividad socialy respuestas críticas desde el pensamiento politico indigena. Guadalajara, CALAS, 2019. 